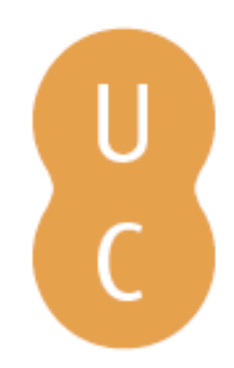

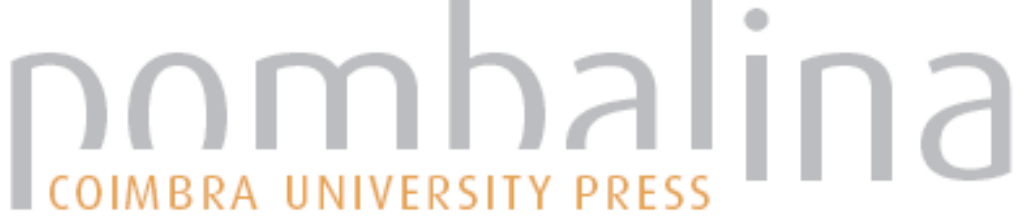

\section{As três culturas}

Autor(es): $\quad$ Antunes, João Lobo

Publicado por: Imprensa da Universidade de Coimbra; Gradiva

URL

persistente:

URI:http://hdl.handle.net/10316.2/32673

DOI:

DOI:http://dx.doi.org/10.14195/978-989-26-0389-6_10

Accessed : $\quad$ 26-Apr-2023 10:07:08

A navegação consulta e descarregamento dos títulos inseridos nas Bibliotecas Digitais UC Digitalis, UC Pombalina e UC Impactum, pressupõem a aceitação plena e sem reservas dos Termos e Condições de Uso destas Bibliotecas Digitais, disponíveis em https://digitalis.uc.pt/pt-pt/termos.

Conforme exposto nos referidos Termos e Condições de Uso, o descarregamento de títulos de acesso restrito requer uma licença válida de autorização devendo o utilizador aceder ao(s) documento(s) a partir de um endereço de IP da instituição detentora da supramencionada licença.

Ao utilizador é apenas permitido o descarregamento para uso pessoal, pelo que o emprego do(s) título(s) descarregado(s) para outro fim, designadamente comercial, carece de autorização do respetivo autor ou editor da obra.

Na medida em que todas as obras da UC Digitalis se encontram protegidas pelo Código do Direito de Autor e Direitos Conexos e demais legislação aplicável, toda a cópia, parcial ou total, deste documento, nos casos em que é legalmente admitida, deverá conter ou fazer-se acompanhar por este aviso. 
C I E N C I A I B E R T A

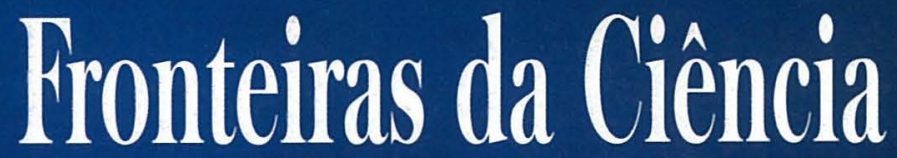

Desenvolvimentos Recentes - Desafios Futuros

RUI FAUSTO • CARLOS FIOLHAIS • JOÃO FILPE QUURRÓ

Coordenadores

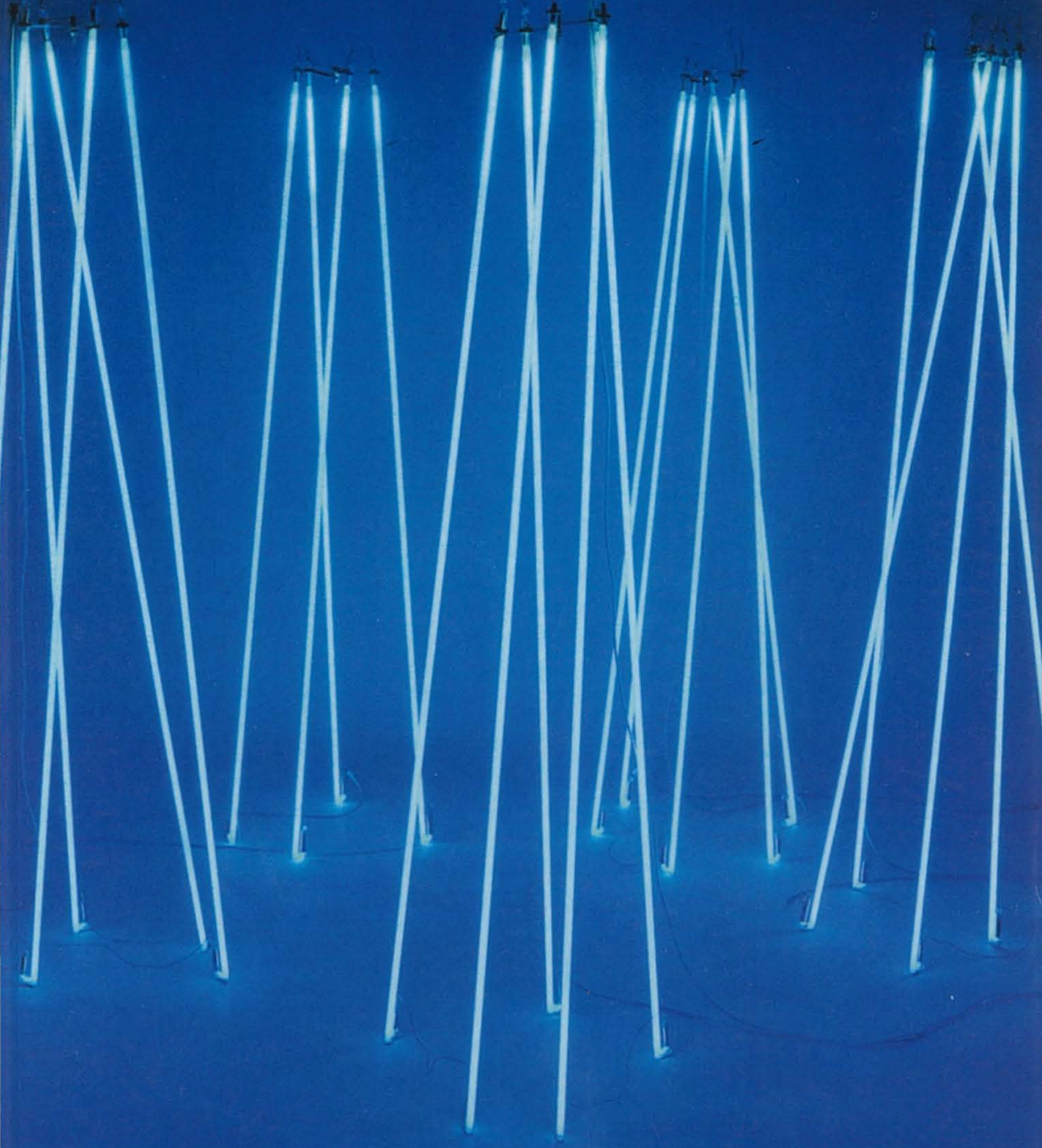

gradiva - Imprensa da Universidade de Coimbra 
(Página deixada propositadamente em branco) 


\section{RUI FAUSTO, CARLOS FIOLHAIS JOÃO FILIPE QUEIRÓ \\ Coordenadores}
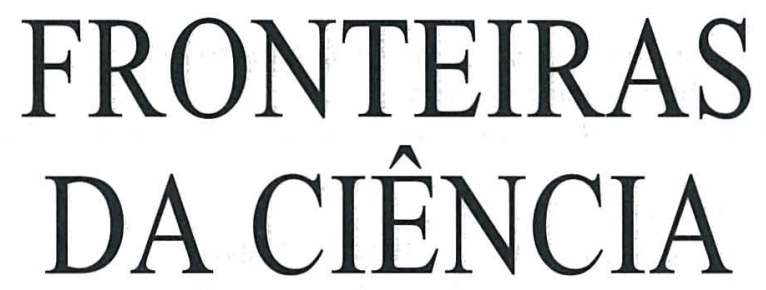

Desenvolvimentos Recentes Desafios Futuros 
(C) Gradiva - Publicações, L. da / Imprensa da Universidade de Coimbra, 2003 Coordenação editorial: Rui Fausto, Carlos Fiolhais e João Filipe Queiró Tradução: Jean Burrows, Vivien Burrows, Rui Fausto, Carlos Fiolhais e João Filipe Queiró

Revisão do texto: Isabel Pedrome

Capa: António Barros [Imprensa da Universidade. Coimbra], sobre imagem de «Águas Vivas», escultura de Silvestre Pestana, 2001

Foto: António Alves; Infografia: ESTÍMULUS [design]; Cortesia: Galeria Alvarez-Arte Contemporânea

Paginação: António Resende e Paula Isabel Jorge

Impressão e acabamento: G.C. - Gráfica de Coimbra, L. ${ }^{d a}$

Reservados os direitos para Portugal por:

Gradiva - Publicações, L. ${ }^{\text {da }}$ e Imprensa da Universidade de Coimbra

Gradiva - Publicações, L.da

Rua Almeida e Sousa, 21, r/c, esq.•1399-041 Lisboa

Telefs. $213974067 / 8 \cdot 213971357 \cdot 213953470$

Fax $213953471 \cdot$ Email: gradiva@ip.pt

URL: http://www.gradiva.pt

Imprensa da Universidade de Coimbra

Rua Antero de Quental, 195 • 3000-033 Coimbra

Telefs. 351239853110

Fax 3512398531 19・e-mail: fjrpress@ci.uc.pt

URL: http://www.imp.uc.pt

ISBN: 972-662-923-3

1." edição: Agosto de 2003

Depósito legal n. ${ }^{\circ} 199$ 463/2003 
João Lobo Antunes

Faculdade de Medicina

Universidade de Lisboa

\section{As três culturas}

Quando tomei conhecimento dos temas deste simpósio, «Fronteiras da Ciência», reparei que do rol de speakers não constava nenhum outro clínico como eu. Pensei pois que, provavelmente, teria algum interesse falar de uma outra fronteira da ciência, ou seja, não da fronteira da ciência pelo lado do saber ou dos limites do conhecimento, mas sim de uma fronteira com a sociedade.

Há já alguns anos, certamente para surpresa dos organizadores de uma reunião, resolvi falar sobre o erro médico. Era um tema que me interessava porque tinha percebido que entre nós, na cultura portuguesa, era uma matéria quase ignorada, que causava grande perplexidade e desconforto. E de facto, pela experiência que eu tivera de catorze anos em Nova Iorque e depois de catorze anos em Lisboa, tinha notado que as diferenças entre os dois países não eram tão substanciais como poderia parecer. Há apenas um desfasamento temporal, porque a questão da novidade científica, a inovação tecnológica e até a ligação médico-industrial e as suas repercussões na cultura médica são fenómenos que existem entre nós. E esta distância, este gap, encurtava-se cada vez mais.

$\mathrm{O}$ que eu gostava de discutir convosco hoje é um assunto provavelmente incómodo para muitos. É que há uma crise, que em Portugal tem um colorido próprio, um tom nacional, que abala as raízes profundas da profissão médica. $\mathrm{E}$ a tendência portuguesa é dizer que estamos a ser ameaçados por uma espécie de matilha invisível, tendo até alguém de 
responsabilidade declarado que nunca nenhum grupo profissional foi até hoje tão perseguido. $\mathrm{Na}$ realidade, trata-se de uma crise universal e a maneira de a enfrentar, como a de resolver qualquer problema em ciência, consiste em analisá-la e em tentar encontrar soluções.

Recuso-me a aceitar que a solução para o problema seja proclamar que as virtudes dos médicos são superiores às de qualquer outra classe científica ou profissional. E nego-me a afirmar que exista uma superioridade moral em relação a médicos de outras nacionalidades ou em relação a outros profissionais. Existem efectivamente matrizes culturais próprias da profissão e do país, e o objecto da antropologia médica é comparar as diferentes culturas.

Por exemplo, a cultura médica francesa atribui ao fígado uma enorme variedade de sintomas - é a chamada crise de foie. Quando regressei a Portugal tive uma grande dificuldade em perceber o que entendia o doente português por «espinhela caída». Mas essa é a face cultural da própria profissão. Quando cheguei aos Estados Unidos não demorei muito tempo a perceber que lá havia uma diferença, um particular toque puritano na maneira como se fazia medicina, um toque que era em parte ingénuo, em parte algo hipócrita.

Mas a crise que afecta a profissão médica é uma crise universal, determinada pelo progresso científico, pelas novas interrogações éticas, por uma nova economia da saúde e pelo questionamento do peso social das profissões, sobretudo das mais poderosas. É isto que tem de ser criticamente analisado pois nego-me a ser membro de uma classe acossada.

Em 1952, Alfred Kroeber e Clyde Kluckohn reviram 164 definições de cultura e acrescentaram outra: a cultura é um produto - é histórica, relativa, aprendida e baseada em símbolos. É uma abstracção colhida dos comportamentos e dos produtos do comportamento. Compreende, portanto, a vida da sociedade, a religião, os seus mitos, a arte, a tecnologia e até o desporto. É toda uma forma de conhecimento sistemático transmitido através de gerações. Assim entendida, parece-me que é legítimo falar-se de uma cultura médica.

Em 1959, Sir Charles Snow mais conhecido por C. P. Snow, proferiu as suas famosas Rede Lectures intituladas Two Cultures. O que ele procurava contrastar era a cultura humanista, a cultura dos letrados, por um lado, e a cultura científica, particularmente a cultura dos físicos, por outro, afirmando que existia entre estas duas formas de cultura um profundo vale de incompreensão e até de hostilidade.

Edward Wilson publicou recentemente um livro intitulado Consilience, que vale a pena ler, onde tenta estabelecer pontes entre as diversas formas de conhecimento. Wilson observa que entre as duas culturas não há uma 
verdadeira separação epistemológica. As fronteiras entre elas constituem na realidade um terreno muito vasto em que há fenómenos que pretendem entrar tanto numa como noutra.

É claro que a tese de C. P. Snow continua a suscitar uma grande controvérsia e uma grande irritação. Pela minha parte, acho que este conceito das duas culturas é muito útil para a medicina porque a medicina é exactamente a ciência capaz de as harmonizar.

Mais recentemente, Kelvin Kelly, num editorial da Science, chamou a atenção para a emergência de uma terceira cultura, uma cultura baseada na tecnologia pela tecnologia. Em termos simples, o seu objectivo é criar a novidade como meio de chegar à experimentação e à verdade; por exemplo, para esta cultura da tecnologia o modo de conhecer o trabalho do cérebro é construir um cérebro que trabalhe. Assim, cria instrumentos mais rapidamente do que novas teorias porque os instrumentos levam ao conhecimento mais rapidamente do que as teorias.

Enquanto a ciência e a arte geram o conhecimento e a beleza, a tecnologia gera a oportunidade. Também a medicina do nosso tempo foi obrigada a abraçar esta nova cultura, imposta cada vez mais por uma classe média global e por um acesso indiscriminado a tecnologias sofisticadas e baratas.

Em três áreas, pelo menos, esta nova cultura tecnológica veio alterar a essência do que nós fazemos.

Em primeiro lugar através do conhecimento. Reparem que o que caracterizava o acto médico era a assimetria do conhecimento: os médicos sabiam coisas que os doentes não sabiam. Agora a tecnologia da informação permite que o saber se torne imediato e universalmente acessível, de forma que o doente conhece melhor os males de que padece e por vezes até testa o conhecimento do médico. Por exemplo, já me tem sucedido o doente fazer-me perguntas muito objectivas, muito precisas, e depois, no fim, dizer: Sim senhor, foi isso mesmo que eu descobri na Internet. Em segundo lugar refiro a tecnologia da imagem, que tornou a doença imediatamente apreensível pelo reconhecimento visual do inimigo, cara a cara, estabelecendo portanto coordenadas epistemológicas muito lineares, ao mesmo tempo simplistas e redutoras de fenómenos extremamente complexos, como são os fenómenos biológicos. A imagem contribui ainda mais para transformar o doente, uma pessoa, num caso.

Em terceiro lugar aponto a introdução de tecnologias a que eu gostaria de chamar «bélicas», ou seja, a eliminação imediata do agressor de uma forma precisa. Recordo que uma das coisas que mais me impressionaram durante a transmissão directa da Guerra do Golfo foi a sensação que se 
pretendia transmitir, de que aquilo era uma guerra limpa, o que a tornava, aparentemente, mais justa. É pois bem compreensível o sucesso que têm tido as técnicas chamadas minimamente invasivas - aquelas em que a doença é eliminada sem marca exterior, sem cicatriz - por um lado, e, por outro, o mito de considerar tecnologias como o laser como a chave terapêutica de muitas doenças.

Mas voltemos ao título da palestra, «as três culturas»; quais são elas?

São a cultura médica, a cultura do capitalismo e a cultura política.

Em primeiro lugar falemos da cultura médica. Esta tem dois pilares fundamentais. $\mathrm{O}$ primeiro ergue-se da herança ancestral de Hipócrates e baseia-se fundamentalmente em dois princípios: o da solidariedade e o do altruísmo. Estes princípios estavam codificados em nove mandamentos, que constituem o juramento de Hipócrates, que os jovens licenciados ainda proferem, provavelmente com algum desconforto porque pelo menos dois dos mandamentos hipocráticos são hoje muito questionados; um diz respeito ao aborto e outro à eutanásia.

É claro que a vivência em plenitude dos princípios hipocráticos é hoje muito difícil. De facto, é complicado compatibilizar uma medicina, que é uma ciência exacta, densa, fáctual, com aquilo a que se pode chamar a arte prudencial, que já vem da tradição aristotélica.

$\mathrm{O}$ que é a arte prudencial? É aquela disposição acompanhada de regra verdadeira, capaz de agir na esfera daquilo que é bom ou mau para o ser humano. É isso que dá sentido à função apostólica de um médico.

Não duvido que a maior parte dos jovens estudantes de medicina respondam a uma vocação, a um chamamento. $\mathrm{E}$, de facto, quando nós, há alguns anos, entrevistámos todos os candidatos ao curso de medicina, o que implicou conversar com novecentos rapazes e raparigas, todos eles afirmaram genuinamente o conceito altruísta de que iam acudir e salvar o seu semelhante.

Hoje em dia muitos sociólogos - não médicos, obviamente - questionam esta história do altruísmo, esta história de nos sacrificarmos para bem do doente. E, de facto, o altruísmo no sentido absoluto, no sentido de corrermos o risco da própria vida, é hoje apenas algo que ficou para uns poucos heróis, nomeadamente os «médicos sem fronteiras». Porque, se analisarmos o comportamento de muitos quando do aparecimento da epidemia da sida, percebia de forma aguda como uma doença arriscada, teríamos uma atitude um pouco mais reservada em relação ao que é o real altruísmo médico. Aliás, não foi muito diferente do que se passou com os médicos medievais durante as epidemias de peste: havia os que fugiam e os que ficavam. 
É claro que há outras reservas em relação ao altruísmo médico. Por exemplo, é bem sabido que hoje o trabalho voluntário quer na medicina, quer noutras profissões, praticamente não existe. As pessoas não oferecem o seu tempo, a sua perícia, em parte, provavelmente, por entenderem que o estado-providência é o responsável por tudo. Mas a actividade caritativa, que era uma componente nuclear da medicina tradicional, hoje praticamente não existe. Mas há dois outros argumentos contra o altruísmo médico: é que, na realidade, os médicos preferem ficar nos grandes centros urbanos, com todas as comodidades sociais, culturais, etc., e só por meio de incentivos económicos se fixam à periferia. Além disso, é também evidente que a escolha de especialidades médicas é determinada por factores económicos. Daí a falta de médicos de família e de clínica geral.

É evidente que o altruísmo continua a ser um valor fundamental e deve ser entendido como doação daquilo que temos de melhor, da nossa inteligência, da nossa vontade, da nossa dedicação e do espírito de renúncia no sentido temporal, valores estes que constituem uma armadura moral indispensável.

A grande questão é saber como se coaduna isto com o segundo componente, este comum a todas as profissões a que chamo learned professions, isto é, profissões baseadas no conhecimento, como a engenharia, a advocacia, ou até, se quiserem, com o munus eclesiástico, ou seja, com os valores do profissionalismo. E o profissionalismo nasceu com as cooperações medievais, que eram inicialmente grupos de profissionais destinados a supervisionar e a regular as actividades de quem praticava uma determinada profissão. Assim, combinavam as aspirações jurídicas, políticas, religiosas e sociais, mas o motivo da sua existência era fundamentalmente o monopólio profissional.

O meu mestre Juvenal Esteves costumava dizer que em Portugal só havia duas corporações genuínas: uma era a Faculdade de Direito da Universidade de Coimbra e a outra eram os Hospitais Civis de Lisboa.

Eu não conheço a Faculdade de Direito da Universidade de Coimbra, mas os Hospitais Civis de Lisboa eram na realidade um corpo extremamente coeso, com um grande rigor na avaliação, por vezes talvez injusta, mas, como dizia John Kennedy, who said that life was fair? O importante é que quem entrava para esta corporação adquiria um selo de qualidade, uma garantia, que a corporação preservava escolhendo apenas os mais aptos.

Ainda hoje, uma das características da profissão médica é o monopólio, ou seja, a defesa da exclusividade da sua prática profissional, um desafio difícil numa altura em que as medicinas alternativas florescem mais do que nunca, sob as mais diversas formas, sendo procuradas não pelos ignorantes, 
mas por pessoas cultas que, de alguma forma, se sentem desiludidas com o insucesso científico da medicina, que lhes frustrou as expectativas. Para a população do nosso século, a morte devia ser apenas uma opção.

Mas os próprios conflitos em relação à tendência monopolista de qualquer profissão nascem no seio da própria profissão e entre os parceiros profissionais. Por exemplo, há um conflito latente entre médicos e enfermeiros na redefinição de qual é, na realidade, o papel de cada grupo na prestação dos cuidados de saúde.

Uma outra característica da cultura profissional é a capacidade de determinar que conhecimentos e aptidões devem ser exigidos e de que forma a competência - e a competência é apenas a ponte entre o conhecimento e a acção - deve ser mantida durante toda a vida profissional. Isto é particularmente importante numa área, como a medicina, em que o conhecimento é explosivo. Havia um professor de Harvard que ensinava Medicina e que dizia eu sei que metade daquilo que vos estou a ensinar já está desactualizado; o meu problema é que eu não sei qual é essa metade... E aqui a questão é como regular esse conhecimento. Daí as duas alternativas: uma é a criação de mecanismos de educação continuada, a outra é a chamada recertificação.

Os mecanismos de educação continuada são muitas vezes, do ponto de vista educativo, apenas uma fraude, pois a sua avaliação é feita de uma forma ligeira e os seus programas não passam de excursões turísticas mais ou menos disfarçadas.

É claro que alguns críticos argumentam que, em relação à medicina, a competência pode ser controlada através de litígio, através da correcção penal ou civil de quem pratica uma má medicina, o que interessa evidentemente aos advogados.

O outro mecanismo é a recertificação, ou seja, o processo pelo qual o médico ou qualquer outro profissional é submetido a exames repetidos, em que a sua competência é avaliada.

Reparem que isto é inaceitável para as organizaçõès sindicais, mas é evidente que quando outras forças, nomeadamente políticas, começam a controlar uma profissão, percebem que uma medicina de qualidade é necessariamente uma medicina mais barata. E, portanto, a manutenção de um certo nível de competência interessa até do ponto de vista económico já para não dizer do ponto de vista social.

Uma outra característica da cultura profissional é a capacidade de disciplinar, de corrigir os malfeitores dentro da profissão castigando quem prevarica, e aí a profissão médica tem sido extraordinariamente permissiva.

Eu próprio fui presidente de um conselho disciplinar e sei das dificuldades de vária natureza que então tinha. Em primeiro lugar, os 
códigos deontológicos e profissionais não se adaptaram às novas condições sócio-económicas da prática da profissão. Por exemplo, no que diz respeito à chamada publicidade médica, a proibição de as pessoas anunciarem o que fazem, as técnicas novas que introduzem na sua prática, tudo isso é considerado proibido e inaceitável e, no entanto, revela-se prática comum. Em segundo lugar, porque não temos grande capacidade de investigar as queixas; muitas vezes espera-se pelo desfecho de processos paralelos que decorrem em tribunais civis ou até criminais. Além disso, reparem que tanto na medicina como noutras áreas, nomeadamente no direito, muitas vezes as opiniões dos técnicos se dividem porque, ao contrário do que se pode pensar, o desenvolvimento da ciência biomédica criou um grande número de incertezas. Por exemplo, em relação a um problema simples como a hérnia discal lombar há pelo menos cinco alternativas para resolver o problema, desde a mais clássica, tradicional, até à mais sofisticada, envolvendo o laser, técnicas minimamente invasivas, etc., técnicas aliás muitas vezes não testadas. Assim, a pronúncia de um juízo técnico é extremamente difícil. É claro que estas justificações não significam que não seja eminentemente correcta a acusação de que a profissão, no fundo qualquer profissão, tem grandes limitações em relação à capacidade de se auto disciplinar.

Finalmente, uma das características das profissões advém-lhes do prestígio profissional, que gera um estatuto de privilégio, o qual cria necessariamente obrigações.

A ponte entre estes dois pilares, a cultura hipocrática e a cultura profissional, reside nos princípios éticos básicos da profissão, dos quais os fundamentais são os princípios da beneficência, da autonomia, do conhecimento e da justiça. Não vou entrar em pormenores, mas reparem que a ética contemporânea põe cada vez mais ênfase na autonomia, ou seja, na capacidade de decidirmos por nós próprios. Mas, na realidade, o estado de doença é um estado de humanidade ferida, e a maior parte de nós, quando estamos doentes, queremos ser tratados como crianças, ser protegidos, ou seja, o paternalismo existe na medicina não como um mal perpetrado pelos profissionais, mas como uma necessidade criada pela doença.

É claro que, à medida que o tempo foi passando, se verificou que a clínica livre, bem ilustrada na figura de João Semana de Júlio Dinis, já não fazia sentido.

A medicina exige tecnologias mais sofisticadas, mais caras, mais poderosas e, pouco a pouco, o médico deixou de ser o seu próprio patrão, proletarizou-se, começou a ser empregado de outrem, do estado ou de instituições privadas. $\mathrm{O}$ famoso «Relatório sobre as carreiras médicas» 
elaborado em 1961 concluiu pela primeira vez que era necessário criar carreiras para os médicos. O médico funcionalizou-se e perdeu automaticamente parte da sua independência, ficando sujeito às regras das outras duas culturas, a cultura do capitalismo e a cultura da política.

$\mathrm{O}$ que quero dizer com a cultura do capitalismo?

Pretendo significar um sistema político-económico organizado em corporações, cujo objectivo fundamental é a produção e o lucro. O que se tem verificado é que se desenvolveu uma cultura empresarial médico-industrial que é uma realidade poderosa e cria uma situação paradoxal, em que, por um lado, se querem preservar valores fundamentais hipocráticos e profissionais e, por outro, o interesse das corporações, em que os médicos estão cada vez mais envolvidos.

O desenvolvimento de tecnologias, de novos fármacos, de meios de diagnóstico, etc., tornou cada vez mais interessante, na perspectiva económica, o investimento na saúde. No passado esse incentivo não era rentável: havia apenas um ou outro médico-empresário que tinha a sua casa de saúde ou investia nas áreas de diagnóstico, até com vantagens sociais, porque o estado é de um modo geral mais lento a adquirir as novas tecnologias. Por exemplo, praticamente todos os avanços na área da imagiologia dependeram da iniciativa privada. Em relação a Portugal não temos dados porque este aspecto é quase tabu. Não temos uma verdadeira investigação sócio-económica do que se passa em Portugal, na área da medicina como noutras áreas. Contudo, por exemplo no estado da Florida, nos Estados Unidos, $40 \%$ dos médicos investem em técnicas auxiliares e $90 \%$ dos laboratórios de imagem estão nas mãos de médicos.

É claro que dirão: e que mal há nisso? Provavelmente há nisso vantagens, e há vantagens porque os médicos conhecem melhor o que serve o doente e podem seleccionar as tecnologias mais adequadas num mercado competitivo. Mas, por outro lado, cria conflitos de interesses, ou seja, o médico possuidor de equipamento de diagnóstico tende a pedir mais exames no seu próprio laboratório. Eu tenho a percepção de que este fenómeno também é conhecido em Portugal, mas não posso demonstrá-lo com números.

Reparem que este boom económico criou dentro da própria classe médica cisões profundas porque interessa a grupos profissionais muito definidos.

E ainda há mais, por exemplo no que diz respeito à relação com a indústria farmacêutica, muito mais complexa do que é apregoado. Por exemplo, no Reino Unido, $60 \%$ da investigação médica é paga pela indústria farmacêutica. Praticamente toda a investigação de novos fármacos, de novas formas de tratar a doença, vem da indústria farmacêutica. 
Também a maioria dos congressos, simpósios, cursos, etc., são pagos pela indústria farmacêutica. A publicidade que faz que muitas revistas médicas sobrevivam é paga pela indústria farmacêutica. Os prémios científicos, com excepção do Prémio Nobel, que foi pago por uma outra indústria, são pagos pela indústria farmacêutica. Portanto, as ligações são muito mais complexas e não se restringem às práticas prescritivas dos médicos.

Um estudo recentemente publicado no New England Journal of Medicine mostrava que os autores que favorecem o uso de determinados medicamentos estão em geral ligados à investigação da sua eficácia. No entanto, nem sempre revelam essa ligação.

Desde que não se ponha em jogo o interesse fundamental do doente, há muito de positivo neste tipo de ligações. Assim, aquele complexo médico-industrial para o qual Relman chamou pela primeira vez a atenção no início dos anos 60 , é hoje uma realidade que tem de ser considerada, que não pode ser escondida.

Consideremos por fim a terceira cultura, a cultura do estado. Era inevitável que a cultura política se intrometesse nisto, reconhecendo que a saúde é um bem social, como a educação, demasiado importante para ser deixada aos profissionais de saúde. É necessário assegurar um acesso universal, apagar as desigualdades, de alguma forma controlar os privilégios. É preciso, portanto, garantir princípios fundamentais como a universalidade na cobertura, a equidade no acesso e a solidariedade no financiamento. De alguma forma, saúde, educação e justiça constituem valores fundamentais que cabe ao estado vigiar.

É claro que a política de esquerda e a política de direita podem ser um pouco diferentes, mas os seus objectivos são os mesmos. Por exemplo, a política chamada de esquerda defende o estado-providência, ataca o poder corporativo, nega a vantagem do fee for service, ou seja, o pagamento individual pelo serviço. A política de direita coexiste melhor com a corporação, apoia a iniciativa privada e de alguma forma favorece o capitalismo. Reparem que a diferença entre a esquerda e a direita, entre a política de um governo socialista e a de um governo social-democrata não é tão grande quanto isso. Em ambos os casos os médicos foram a pouco e pouco submetidos àquilo que Max Weber chamava the iron cage of bureaucratisation. O segundo controlo político vem dos preços: o governo paga a conta e exige qualidade e rentabilidade. A ideia, que tantas vezes ouvimos exprimir, de que a saúde não tem preço é errada. A saúde tem preço e é muito cara, e a capacidade de aplicar ou decidir onde se vai investir é uma decisão eminentemente política.

O terceiro controlo vem daquilo que disse há pouco: como os médicos não se auto disciplinam, os políticos intervêm, muitas vezes até através 
de uma aliança, curiosa, com os meios de comunicação social. A notícia do erro médico, da catástrofe médica, vende, sempre vendeu jornais.

Um último passo foi retirar os médicos a definição exclusiva dos princípios éticos que regem a profissão, e partilhá-la com sociólogos, filósofos, religiosos, leigos, etc.

Há quem pense que as comissões de ética nasceram para proteger os doentes dos seus médicos. Devo dizer que a minha interpretação é completamente diferente. Eu assisti ao nascimento das comissões de ética, que surgiram pela necessidade de reflectir sobre problemas novos, que não sabíamos resolver, tais como a morte cerebral, o problema dos tratamentos prolongados quando não havia esperança, a eutanásia, as malformações congénitas dos recém-nascidos, etc. Portanto, foi necessária uma nova reflexão, uma nova maneira de pensar.

A cultura política tem agora uma outra extensão, que é a extensão europeia. É o super-estado, é a livre circulação de médicos. O monopólio corporativo foi abalado porque as regras agora são outras, são ditadas por Bruxelas, e fundamentalmente por interesses económicos. $\mathrm{E}$ assim vemos como se casam a cultura política e a cultura económica.

Isto significa, portanto, que os paradigmas da prática médica se alteraram substancialmente, ou seja, a prática individual está hoje em dia espartilhada por guidelines, os custos passaram a ser uma consideração primária, a qualidade começa a ser definida por resultados, por metas. E estas não são necessariamente ditadas pelo grau de satisfação do doente. De facto, o doente ideal do ponto de vista empresarial é aquele que não tem qualquer doença, ou aquele cuja doença é barata; os doentes mandam-se para casa quicker and sicker, ou seja, o mais depressa e o mais doentes possível.

Da gestão da doença passou-se para a gestão da saúde, e a autonomia do médico foi substituída pela interdependência científica, profissional e administrativa. Do médico como figura central do hospital passou-se para o médico com um papel na gestão - muitas vezes, como eu digo, patrão na faculdade e servo no hospital. Qual é a solução?

Penso que esta análise só tem sentido se, na realidade, pretendermos tirar disto uma lição e, ao mesmo tempo, ultrapassar a crise e tentar definir novos caminhos. Há uma verdade fundamental: ainda temos um grande capital de prestígio. A profissão médica continua a ser classificada em primeiro lugar na perspectiva do prestígio social. Em segundo lugar, o avanço biomédico não pára e gera novas formas de tratamento, novos conhecimentos a respeito do ser humano. Por outro lado, a competência técnica é hoje em dia muito mais visível.

É pois prudente manter os valores da profissão, como o altruísmo, a compaixão, a integridade e a verdade, e, ao mesmo tempo, aceitar que o 
dinheiro é escasso e que não se pode ter tudo. Depois é fundamental fazer aquilo que eu não tenho visto até agora, e que acho muito importante, que é dissociar o discurso político do discurso técnico. Quando o discurso político ocupa todo o espaço esquecem-se valores fundamentais. Isto aplica-se aliás também à própria universidade. Quando o discurso académico é ocupado apenas pelo problema do financiamento não fica muito espaço para se falar de outras coisas. Depois é preciso ainda definir bem os princípios da cultura empresarial, que é legítima, mas tem regras. É por isso que penso que a liderança não pode ser reactiva, defensiva, cripto-sindicalista e isolacionista.

Finalmente, é preciso entender que os médicos têm de aprender gestão, têm de adquirir uma outra cultura a que são naturalmente adversos, e aí os conflitos das duas culturas, por princípio, têm de ser conciliados.

Alexandre Quintanilha disse uma coisa muito importante que talvez tenha passado despercebida a alguns. Quando falamos de educação, evocamos imediatamente as pessoas que nos marcaram.

A mim, o homem que me ensinou a pensar em termos clínicos e científicos foi o Dr. Edward Schesinger, que faleceu há pouco tempo. Ele era, de facto, um humanista no sentido pleno, um homem com uma grande cultura literária. Um dos livros que ele me aconselhou foi um romance de George Elliot, Middlemarch. É um romance grande, um fresco magnífico com várias personagens que aparecem e desaparecem. George Elliot, uma mulher que escrevia com nome de homem, provavelmente porque as suas teses desafiavam a sociedade da altura, adverte no romance que o carácter não é esculpido em pedra, mas em algo de vivo e alterável que, tal como o corpo, também adoece.

Uma das personagens desse livro era o Dr. Lydgate, que surge no início como um jovem médico idealista, determinado a tratar dos pobres e a fazer avançar o conhecimento realizando investigação. No final da obra, quando o destino das personagens é passado em revista, afirma-se a propósito de Lydgate: He had gained an excellent practice alternating, according to the season, between London and a continental bathing-place; having written a treatise on gout, a disease which has a good deal of wealth on its side. His skill was relied on by many paying patients, but he always regarded himself as a failure: he had not done what he once meant to do.

Não será também esta a fonte do nosso desconforto? 
 \\ A palavra "fronteiras" pode ser tomada em} diferentes sentidos. Pode referir-se aos limites, necessariamente provisórios, entre o conhecido e o desconhecido, ou aos limites entre o possivel e o impossivel, e, dentro do possivel, entre o desejável e 0 indesejável. Fronteiras podem também ser as delimitações, nem sempre nítidas, entre ciência e não-ciência, e dentro da ciência, entre as várias disciplinas. Quais são então as fronteiras da ciência?

Neste livro, a resposta a esta pergunta é dada, segundo as mais diferentes perspectivas, por um conjunto notável de personalidades, cientistas ou não, entre as quais se contam três Prémios Nobel.

Rui Fausto, Carlos fiolhais e JoÃo Fillipe Queiró são, respectivamente, professores de Química, Física e Matemática na Faculdade de Ciências e Tecnologia da Universidade de Coimbra. 